\section{(6) OPEN ACCESS}

\title{
Is chlamydia screening and testing in Britain reaching young adults at risk of infection? Findings from the third National Survey of Sexual Attitudes and Lifestyles (Natsal-3)
}

\author{
Sarah C Woodhall, ${ }^{1,2}$ Kate Soldan, ${ }^{2}$ Pam Sonnenberg, ${ }^{1}$ Catherine H Mercer, ${ }^{1}$ \\ Soazig Clifton, ${ }^{1,3}$ Pamela Saunders, ${ }^{4}$ Filomeno da Silva, ${ }^{4}$ Sarah Alexander, ${ }^{4}$ \\ Kaye Wellings, ${ }^{5}$ Clare Tanton, ${ }^{1}$ Nigel Field, ${ }^{1}$ Andrew J Copas, ${ }^{1}$ Catherine A Ison, ${ }^{4}$ \\ Anne M Johnson ${ }^{1}$
}

- Additional material is published online only. To view please visit the journal online (http://dx.doi.org/10.1136/ sextrans-2015-052013).

For numbered affiliations see end of article.

\section{Correspondence to}

Sarah C Woodhall, HIV \& STI Department, Public Health

England, 61 Colindale Avenue, London NW9 5EQ, UK; sarah.woodhall@phe.gov.uk

Received 16 January 2015 Revised 29 May 2015 Accepted 12 July 2015 Published Online First 19 August 2015

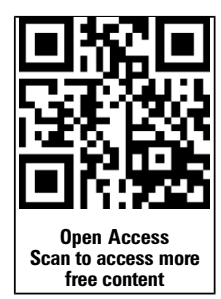

\section{ABSTRACT}

Background In the context of widespread opportunistic chlamydia screening among young adults, we aimed to quantify chlamydia testing and diagnosis among 16-24 year olds in Britain in relation to risk factors for prevalent chlamydia infection.

Methods Using data from sexually experienced $(\geq 1$ lifetime sexual partner) 16-year-old to 24-year-old participants in Britain's third National Survey of Sexual Attitudes and Lifestyles (conducted 2010-2012), we explored socio-demographic and behavioural factors associated with prevalent chlamydia infection (detected in urine; $n=1832$ ), self-reported testing and self-reported diagnosis in the last year (both $n=3115$ ).

Results Chlamydia prevalence was 3.1\% $(95 \% \mathrm{Cl}$ $2.2 \%$ to $4.3 \%)$ in women and $2.3 \%(1.5 \%$ to $3.4 \%)$ in men. A total of $12.3 \%$ of women and $5.3 \%$ men had a previous chlamydia diagnosis. Factors associated with prevalent infection were also associated with testing and diagnosis (eg, increasing numbers of sexual partners), with some exceptions. For example, chlamydia prevalence was higher in women living in more deprived areas, whereas testing was not. In men, prevalence was higher in 20-24 than 16-19 year olds but testing was lower. Thirty per cent of women and $53.7 \%$ of men with $\geq 2$ new sexual partners in the last year had not recently tested.

Conclusions In 2010-2012 in Britain, the proportion of young adults reporting chlamydia testing was generally higher in those reporting factors associated with chlamydia. However, many of those with risk factors had not been recently tested, leaving potential for undiagnosed infections. Greater screening and prevention efforts among individuals in deprived areas and those reporting risk factors for chlamydia may reduce undiagnosed prevalence and transmission.

\section{INTRODUCTION}

Chlamydia trachomatis ('chlamydia') is the most commonly diagnosed sexually transmitted infection (STI) in the UK. ${ }^{1}$ Most chlamydia infections are asymptomatic, and untreated infections can cause serious complications including pelvic inflammatory disease, ectopic pregnancy and tubal factor infertility in women. ${ }^{2}$ By diagnosing and treating asymptomatic infections, chlamydia screening potentially reduces the risk of complications ${ }^{3}$ and is expected to reduce chlamydia prevalence and transmission. ${ }^{4}$ In England, the National Chlamydia Screening Programme (NCSP) recommends that sexually active under 25 year olds are tested annually and on change of sexual partner. ${ }^{5}$ Chlamydia screening is offered opportunistically in clinical and non-clinical settings in England. Scotland and Wales do not have an organised screening programme; guidelines recommend asymptomatic testing of young adults ${ }^{6-8}$ with a focus on those at high risk (eg, those reporting multiple sexual partners in the last year, those with a previous diagnosis or patients attending genitourinary medicine (GUM) clinics).

Chlamydia testing of young adults increased substantially in the UK over the last decade. Increases in testing occurred in GUM clinics as a result of improved access to sexual health services ${ }^{9-11}$ and availability of diagnostic testing using non-invasive samples. ${ }^{12}$ In England, a major increase was driven by the national scale-up of the NCSP. After a phased roll-out from 2003 to 2008, a step change in screening activity outside of GUM clinics was seen from 2008 to 2010 as local areas responded to national targets for testing coverage. ${ }^{13}$ Testing coverage (number of tests divided by total 15 -year-old to 24-year-old population) peaked at $34 \%$ in 2010 and fell slightly to $30 \%$ and $26 \%$ in 2011 and 2012, respectively. ${ }^{14} 15$

The third National Survey of Sexual Attitudes and Lifestyles (Natsal-3) is a stratified crosssectional probability sample survey of adults resident in Britain (England, Scotland and Wales; Northern Ireland was not included). ${ }^{16}$ Conducted from 2010 to 2012, Natsal-3 included anonymous testing of urine specimens for STI, including chlamydia, and asked questions on chlamydia testing and diagnosis history. The survey provides a unique opportunity to investigate patterns of chlamydia infection and testing within a nationally representative sample of the British population.

Sonnenberg et al previously reported an overview of STI prevalence and service use using data from 
Natsal-3. ${ }^{17}$ Chlamydia prevalence in $16-44$ year olds was $1.5 \%$ in women and $1.1 \%$ in men and was higher among $16-24$ year olds (women: 3.1\%; men: 2.3\%). Among 16-24 year olds, $54.2 \%$ of women and $34.6 \%$ of men reported testing in the last year. Although prevalence was reported by age group, factors associated with prevalent infection were assessed among all 1644 year olds. Only a limited number of factors associated with chlamydia prevalence and testing were explored (age group, arealevel deprivation, sexual partners in the last year, sexual partners in the last year without a condom (investigated for prevalence only), age at first sex and any same-sex experience). In this paper, we report a detailed analysis among 16-24 year olds in Britain as this is the age group targeted by the NCSP in England. We describe and compare factors associated with prevalent chlamydia infection, previous chlamydia diagnosis and chlamydia testing to assess the extent to which opportunistic chlamydia screening is reaching young adults at risk of chlamydia.

\section{METHODS}

\section{Participants and procedures}

In Natsal-3, participants were interviewed using computerassisted face-to-face and computer-assisted self-interview for the most sensitive questions. The overall response rate was $57.7 \%$, in line with other major social surveys conducted in Britain around the same time, ${ }^{18} 19$ achieving a sample of 15162 16-74 year olds. ${ }^{16}$ A subset of participants, including all 16-17 year olds (regardless of reported sexual activity) and 18-24 year olds who reported at least one sexual partner by the time of the interview (hereafter termed 'sexually experienced') were invited to provide a urine sample for anonymous STI testing. ${ }^{16}{ }^{17}$ Participants did not receive their test results. ${ }^{20}$ Of all Natsal-3 respondents eligible for the urine study, $57 \%$ provided a sample. Urine samples were posted to Public Health England where they were batch-tested for chlamydia using the Aptima Combo 2 assay (Hologic Gen-Probe); positive and equivocal results were confirmed with the Aptima chlamydia monospecific assay. ${ }^{17}$ Details of the survey methods and questionnaire are available elsewhere. ${ }^{16}$

We estimated the prevalence of chlamydia detected in urine (hereafter termed 'prevalent infection'), self-reported chlamydia test in the last year ('recent testing'), self-reported chlamydia diagnosis in the last year ('recent diagnosis') and self-reported chlamydia diagnosis ever.

A flow chart of participants included in our analyses is presented in the online supplementary material. Analyses of recent testing and recent diagnosis were based on sexually experienced $16-24$ year olds $(n=3115)$. Analyses of prevalent infection were among those who provided a urine sample for STI testing and for whom a valid chlamydia test result is available $(n=1832,62$ of whom had a prevalent infection).

\section{Statistical analyses}

Analyses were carried out using Stata V.12.1, accounting for weighting, clustering and stratification of the data. Survey weights were applied to adjust for unequal probability of selection and non-response to make the sample data broadly representative of the British general population, according to the 2011 Census, in terms of sex, age group and Government Office Region. ${ }^{16}$ Willingness to provide a urine sample varied by demographic and behavioural variables, including age, number of sexual partners (by the time of the interview/without a condom in the last year), same-sex experience and sexual health clinic attendance. Estimates of prevalent infection were therefore given an additional weight to reduce bias in the profile of urine sample respondents. ${ }^{16} 21$
Factors associated with prevalent infection, recent diagnosis and recent testing were investigated using univariable and multivariable logistic regression, for women and men separately. Although the overall percentage diagnosed with chlamydia (ever or in the last year) was estimated among the sexually experienced population, risk factors for recent diagnosis were investigated among those with a recent test to investigate associations with being infected at the time of testing rather than with testing per se. Socio-demographic and behavioural factors previously demonstrated to be associated with STI risk were included as predictor variables. ${ }^{22-24}$ Associations with deprivation were explored using both residence-based (quintile of Index of Multiple Deprivation (IMD) for the lower layer super output area (LSOA) of residence (a geographical area of around 1500 people $\left.^{25}\right)$ ) and individual-based (age left school) measures. Sexual behaviours investigated included numbers of sexual partners in the last year (total, new, without a condom), number of sexual partners by the time of the interview (hereafter 'lifetime sexual partners') and condom use at last sex. Frequency of binge drinking was included as a proxy for sexual risk behaviour that may not be captured in reported numbers of sexual partners.

With two exceptions, all variables included in univariable models were included in multivariable models: number of sexual partners in the last year was not included due to collinearity with other sexual partnership variables; age left school was not included as data were unavailable for 16 year olds.

To explore how chlamydia infections were distributed across population subgroups, we calculated the percentage reporting selected socio-demographic and behavioural factors among (a) individuals with a prevalent infection, (b) individuals recently diagnosed and (c) the sexually experienced population.

\section{RESULTS}

Table 1 shows chlamydia prevalence and self-reported chlamydia testing and diagnosis in the last year among sexually experienced 16-24 year olds. Around two-thirds (62.5\%) of women and $43.2 \%$ of men had either been tested or offered a test in the last year. A total of $12.3 \%$ of women and $5.3 \%$ men had ever been diagnosed with chlamydia.

Among those recently tested, $<10 \%$ reported a clinical indication (symptoms; a partner with chlamydia/symptoms; check-up after a previous diagnosis) for their last test. Around threequarters of women and half of men had last been tested in a sexual health clinic, general practice (GP) surgery or family planning clinic. Almost all (95.4\%) individuals recently diagnosed had most recently been tested in one of these settings. Half of those recently diagnosed had last been tested due to symptoms or having a partner with chlamydia/symptoms (table 2).

Tables 3 and 4 explore the associations between sociodemographic and behavioural variables and prevalent infection, recent testing and recent diagnosis. In univariable analyses, higher numbers of sexual partners (total/new/without a condom $)$ in the last year were significantly $(\mathrm{p}<0.05)$ associated with prevalent infection among women and men. In women, area-level deprivation (measured at LSOA level) and frequency of binge drinking were also associated with prevalent infection. Among men, number of lifetime sexual partners, age group, age left school, age at first sex and condom non-use at last sex were significantly associated with prevalent infection. Similar factors were associated with recent diagnosis among those tested. In multivariable analyses, living in more deprived areas and more frequent binge drinking remained significantly associated with having a prevalent infection in women. Older age group, living 
Table 1 Prevalence of chlamydia infection detected in urine and of self-reported testing and diagnosis by sex (sexually experienced 16-24 year olds)

\begin{tabular}{|c|c|c|c|c|c|c|}
\hline & \multicolumn{2}{|c|}{ Women } & \multicolumn{2}{|l|}{ Men } & \multicolumn{2}{|c|}{$\begin{array}{l}\text { Denominator* } \\
\text { (weighted, unweighted) }\end{array}$} \\
\hline & $\%$ & $95 \% \mathrm{Cl}$ & $\%$ & $95 \% \mathrm{Cl}$ & Women & Men \\
\hline Prevalent chlamydia infection detected in urine & 3.1 & 2.2 to 4.3 & 2.3 & 1.5 to 3.4 & 597, 992 & 625,840 \\
\hline Tested for chlamydia in the last year & 54.2 & 51.4 to 56.9 & 34.6 & 31.9 to 37.4 & 966,1736 & 1003,1375 \\
\hline Offered, not tested for chlamydia in the last year & 8.3 & 6.9 to 9.9 & 8.6 & 7.0 to 10.4 & 966,1735 & 1001,1373 \\
\hline Diagnosed with chlamydia in the last year & 3.0 & 2.2 to 4.0 & 2.0 & 1.3 to 3.0 & 962,1727 & 992,1364 \\
\hline Ever diagnosed with chlamydia & 12.3 & 10.6 to 14.1 & 5.3 & 4.1 to 6.7 & 962,1727 & 992,1364 \\
\hline
\end{tabular}

*Denominators for recent testing/offer of testing and for diagnosis (recent or ever) differ due to item-missingness.

$95 \% \mathrm{Cl}$ of unadjusted OR and $\mathrm{p}$ values for unadjusted and adjusted OR are presented in full in the online supplementary material.

in more deprived areas and higher numbers of lifetime sexual partners remained significantly associated with prevalent infection in men.

Figure 1 shows unadjusted ORs for prevalent infection and recent testing by socio-demographic and behavioural factors. Groups in the upper right hand quadrant are those where both the odds of prevalent infection and of testing were higher than the reference group. Groups in the upper-left-hand quadrant had higher odds of prevalent infection, but lower odds of testing than the reference group. Factors associated with recent testing were similar to those associated with prevalent infection, with some exceptions. Whereas women living in one of the two most deprived IMD quintiles had almost four times higher odds of prevalent infection versus those living in less deprived areas (OR 3.82, 95\% CI 1.35 to 10.79 ), the odds of recent testing did not differ by deprivation (OR $0.99,0.77$ to 1.27 ). Among men, the odds of prevalent infection were higher among $20-24$ vs 1619 year olds (OR 10.6, 2.40 to 46.3), but odds of recent testing were lower in the older age group (OR $0.67,0.44$ to 0.84 ). In men, not having used a condom at last sex was associated with a sixfold increase in the odds of prevalent infection (OR 6.03, 1.87 to 19.42), but was not associated with recent testing (OR 1.22, 0.95 to 1.56). Similar patterns were seen when comparing adjusted ORs from multivariable models (tables 3 and 4).
Although the proportion recently tested was generally higher in those reporting risk factors for chlamydia, recent testing remained well below 100\% in all socio-demographic and behavioural subgroups. For example, $30.0 \%$ of women and $53.7 \%$ of men with $\geq 2$ new sexual partners in the last year and $25.8 \%$ of women and $51.2 \%$ of men reporting $\geq 2$ sexual partners without a condom in the last year had not been recently tested (tables 3 and 4).

Among individuals with a prevalent chlamydia infection, 14\% (95\% CI $7 \%$ to $14 \%$ ) had ever been diagnosed with chlamydia and $5 \%(2 \%$ to $17 \%)$ reported a diagnosis in the last year (indicating either repeat or persistent infections). Fifty per cent (35-64\%) of those with a prevalent infection reported a recent chlamydia test $(89 \%$ of whom did not report a recent diagnosis, thus indicating incident infections within the last year). Over two-thirds of prevalent infections were among individuals resident in one of the $40 \%$ most deprived LSOA. Infections in women were more evenly distributed by numbers of sexual partners than in men. For example, among men, $80 \%$ of those with a prevalent infection and $77 \%$ of those recently diagnosed reported $\geq 10$ lifetime sexual partners versus only $25 \%$ of the population. In women, $35 \%$ of those with a prevalent infection reported $\geq 10$ lifetime sexual partners versus $21 \%$ of the population (see online supplementary table S1).

Table 2 Reason and location of most recent chlamydia test, among those tested for chlamydia in the last year, by sex and by whether diagnosed in last year (sexually experienced 16-24 year olds)

\begin{tabular}{|c|c|c|c|c|c|c|c|c|}
\hline & \multicolumn{4}{|c|}{ By sex } & \multicolumn{4}{|c|}{ By whether diagnosed in the last year* } \\
\hline & \multicolumn{2}{|c|}{ Women } & \multicolumn{2}{|l|}{ Men } & \multicolumn{2}{|c|}{$\begin{array}{l}\text { Diagnosed in the last } \\
\text { year }\end{array}$} & \multicolumn{2}{|c|}{$\begin{array}{l}\text { Not diagnosed in } \\
\text { the last year }\end{array}$} \\
\hline & $\%$ & $95 \% \mathrm{Cl}$ & $\%$ & $95 \% \mathrm{Cl}$ & $\%$ & $95 \% \mathrm{Cl}$ & $\%$ & $95 \% \mathrm{Cl}$ \\
\hline Denominator (weighted, unweighted) & \multicolumn{2}{|c|}{523,943} & \multicolumn{2}{|c|}{347,475} & \multicolumn{2}{|c|}{48,81} & \multicolumn{2}{|c|}{816,1330} \\
\hline \multicolumn{9}{|l|}{ Reason for most recent test } \\
\hline Had symptoms & 4.2 & 3.0 to 5.8 & 4.2 & 2.7 to 6.5 & 29.0 & 19.0 to 41.5 & 2.7 & 1.9 to 3.8 \\
\hline Partner diagnosed with chlamydia or had symptoms & 2.8 & 1.7 to 4.5 & 3.8 & 2.4 to 6.1 & 20.9 & 12.8 to 32.2 & 2.2 & 1.4 to 3.4 \\
\hline Check up after a previous positive & 1.3 & 0.63 to 2.6 & 0.95 & 0.33 to 2.7 & 8.6 & 3.2 to 21.1 & 0.7 & 0.4 to 1.4 \\
\hline Wanted a check-up/offered a test/worried about risk & 84.9 & 82.1 to 87.4 & 87.3 & 83.8 to 90.1 & 37.2 & 26.2 to 49.86 & 88.7 & 86.8 to 90.4 \\
\hline Other & 6.8 & 5.3 to 8.7 & 3.7 & 2.3 to 6.0 & 4.3 & 1.5 to 12.0 & 5.7 & 4.5 to 7.1 \\
\hline \multicolumn{9}{|l|}{ Location of most recent chlamydia test } \\
\hline Sexual health clinic & 28.9 & 25.5 to 32.6 & 30.5 & 25.9 to 35.5 & 62.9 & 50.4 to 73.9 & 27.6 & 25.0 to 30.4 \\
\hline GP surgery & 35.1 & 31.7 to 38.6 & 17.0 & 13.6 to 20.9 & 27.1 & 17.7 to 39.1 & 28.0 & 25.3 to 30.8 \\
\hline NHS Family Planning clinic & 9.2 & 7.4 to 11.4 & 4.3 & 2.7 to 6.8 & 5.4 & 1.6 to 16.3 & 7.3 & 6.0 to 8.9 \\
\hline School, college or university & 11.6 & 9.4 to 14.2 & 24.5 & 20.4 to 29.1 & 1.7 & 0.4 to 7.2 & 17.5 & 15.2 to 20.1 \\
\hline Elsewhere & 15.2 & 12.9 to 17.8 & 23.8 & 19.3 to 28.9 & 2.9 & 1.0 to 8.1 & 19.6 & 17.2 to 22.2 \\
\hline
\end{tabular}


Table 3 Percentage, unadjusted and adjusted ORs for prevalent chlamydia infection, self-reported diagnosis in the last year and self-reported testing by socio-demographic and behavioural factors (sexually experienced 16-24 year old women)

\begin{tabular}{|c|c|c|c|c|c|c|c|c|c|c|c|c|c|c|c|c|c|c|}
\hline & \multicolumn{5}{|c|}{ Prevalent infection detected in urine $(n=992)$} & \multicolumn{5}{|c|}{$\begin{array}{l}\text { Diagnosed with chlamydia in the last year } \\
\text { (among those tested in the last year) }(\mathrm{n}=940)\end{array}$} & \multicolumn{5}{|c|}{ Tested for chlamydia in the last year $(n=1736)$} & \multicolumn{3}{|c|}{$\begin{array}{l}\text { Denominator (weighted, } \\
\text { unweighted)* }\end{array}$} \\
\hline & $\%$ & $95 \% \mathrm{Cl}$ & OR & AORT & $95 \% \mathrm{Cl}$ & $\%$ & $95 \% \mathrm{Cl}$ & OR & AORT & $95 \% \mathrm{Cl}$ & $\%$ & $95 \% \mathrm{Cl}$ & OR & AORT & $95 \% \mathrm{Cl}$ & Infection & Diagnosis & Tested \\
\hline \multicolumn{19}{|l|}{ Age group } \\
\hline $16-19$ & 3.8 & 2.2 to 6.3 & 1.00 & 1.00 & - & 6.0 & 3.8 to 9.2 & 1.00 & 1.00 & - & 56.6 & 52.5 to 60.6 & 1.00 & 1.00 & - & 214,395 & 193, 375 & 343,672 \\
\hline $20-24$ & 2.7 & 1.7 to 4.3 & 0.71 & 0.71 & 0.27 to 1.87 & 5.1 & 3.4 to 7.6 & 0.86 & 0.80 & 0.35 to 1.78 & 52.8 & 49.2 to 56.4 & 0.86 & 0.82 & 0.62 to 1.07 & 383,597 & 329,565 & 623,1064 \\
\hline \multicolumn{19}{|l|}{ Country } \\
\hline England & 2.9 & 2.0 to 4.3 & 1.00 & 1.00 & - & & & & & & 57.1 & 54.1 to 60.1 & 1.00 & 1.00 & - & 504,817 & 469,832 & 823,1452 \\
\hline Scotland & 3.1 & 1.1 to 8.6 & 1.08 & 1.34 & 0.43 to 4.14 & & & & & & 32.4 & 24.4 to 41.5 & 0.36 & 0.29 & 0.18 to 0.45 & 56,103 & 30,58 & 91,178 \\
\hline Wales & 5.3 & 1.9 to 13.8 & 1.87 & 1.88 & 0.63 to 5.54 & & & & & & 45.6 & 36.2 to 55.4 & 0.63 & 0.53 & 0.32 to 0.85 & 37,72 & 24,50 & 52,106 \\
\hline \multicolumn{19}{|c|}{ IMD quintile of $L S O A$ of residence§ } \\
\hline 2 least deprived & 1.3 & 0.5 to 3.4 & 1.00 & 1.00 & - & 4.8 & 2.8 to 8.1 & 1.00 & 1.00 & - & 54.2 & 49.5 to 58.8 & 1.00 & 1.00 & - & 213,355 & 183,319 & 338,595 \\
\hline Middle quintile & 1.8 & 0.8 to 4.2 & 1.37 & 1.40 & 0.39 to 4.98 & 3.5 & 1.6 to 7.3 & 0.71 & 1.06 & 0.37 to 3.04 & 54.4 & 48.0 to 60.7 & 1.01 & 1.03 & 0.71 to 1.48 & 111,174 & 102,176 & 189,324 \\
\hline 2 most deprived & 4.9 & 3.3 to 7.3 & 3.82 & 4.23 & 1.53 to 11.6 & 6.8 & 4.6 to 10.0 & 1.46 & 1.70 & 0.73 to 3.91 & 54.0 & 49.8 to 58.2 & 0.99 & 0.97 & 0.73 to 1.29 & 273,463 & 236,445 & 439,817 \\
\hline \multicolumn{19}{|l|}{ Age left schooløt† } \\
\hline $17+$ & 3.2 & 2.1 to 4.8 & 1.00 & & & 5.2 & 3.6 to 7.5 & 1.00 & & & 54.3 & 51.0 to 57.6 & 1.00 & & & 445,700 & 387,658 & 715,1217 \\
\hline 16 & 3.4 & 1.9 to 6.0 & 1.06 & & & 6.2 & 3.7 to 10.5 & 1.21 & & & 55.5 & 50.1 to 60.8 & 1.05 & & & 120,229 & 109,228 & 196,405 \\
\hline \multicolumn{19}{|c|}{ Age at first heterosexual sex } \\
\hline $17+$ & 1.6 & 0.7 to 3.7 & 1.00 & 1.00 & - & 4.1 & 1.8 to 8.9 & 1.00 & 1.00 & - & 43.9 & 38.7 to 49.1 & 1.00 & 1.00 & - & 188,246 & 137,215 & 313,489 \\
\hline 16 & 3.9 & 2.1 to 6.9 & 2.52 & 2.20 & 0.67 to 7.17 & 5.0 & 2.8 to 8.9 & 1.24 & 0.80 & 0.26 to 2.42 & 56.4 & 51.6 to 61.1 & 1.66 & 1.39 & 0.99 to 1.92 & 178,304 & 154, 272 & 273,503 \\
\hline$<16$ & 4.0 & 2.4 to 6.6 & 2.65 & 1.82 & 0.60 to 5.42 & 6.9 & 4.8 to 9.9 & 1.76 & 0.89 & 0.35 to 2.25 & 63.9 & 59.8 to 67.9 & 2.27 & 1.44 & 1.05 to 1.97 & 213,415 & 220,429 & 344,680 \\
\hline \multicolumn{19}{|c|}{ Number of sexual partners in the last yeart† } \\
\hline 0 or 1 & 2.5 & 1.5 to 4.0 & 1.00 & & & 3.0 & 1.7 to 5.4 & 1.00 & & & 46.6 & 43.3 to 50.0 & 1.00 & & & 387,600 & 291,507 & 624,1096 \\
\hline 2 & 3.9 & 1.8 to 8.5 & 1.62 & & & 6.6 & 3.7 to 11.6 & 2.25 & & & 65.2 & 58.8 to 71.1 & 2.15 & & & 90,161 & 93,178 & 143,275 \\
\hline $3-4$ & 1.9 & 0.7 to 5.1 & 0.75 & & & 8.8 & 5.2 to 14.6 & 3.08 & & & 69.7 & 62.0 to 76.4 & 2.63 & & & 63,127 & 76,146 & 111,210 \\
\hline $5+$ & 8.3 & 3.9 to 16.8 & 3.57 & & & 11.6 & 6.2 to 20.8 & 4.19 & & & 74.8 & 64.4 to 83.0 & 3.40 & & & 49,93 & 58,101 & 77,135 \\
\hline \multicolumn{19}{|c|}{ Number of new sexual partners in the last year } \\
\hline 0 & 2.2 & 1.3 to 3.7 & 1.00 & 1.00 & - & 2.8 & 1.5 to 5.0 & 1.00 & 1.00 & - & 45.6 & 41.9 to 49.3 & 1.00 & 1.00 & - & 313,495 & 226,397 & 495,873 \\
\hline 1 & 2.8 & 1.2 to 6.3 & 1.26 & 1.17 & 0.38 to 3.52 & 4.8 & 2.5 to 9.1 & 1.76 & 1.89 & 0.69 to 5.16 & 59.2 & 54.0 to 64.2 & 1.73 & 1.69 & 1.25 to 2.27 & 160,263 & 156, 287 & 264,485 \\
\hline $2+$ & 5.9 & 3.5 to 9.8 & 2.73 & 1.65 & 0.50 to 5.39 & 10.7 & 7.3 to 15.6 & 4.23 & 3.09 & 1.07 to 8.86 & 70.0 & 63.8 to 75.6 & 2.79 & 1.46 & 0.95 to 2.21 & 118,225 & 137,249 & 197,359 \\
\hline \multicolumn{19}{|c|}{ Number of sexual partners in the last year without a condom } \\
\hline 0 & 2.9 & 1.2 to 7.1 & 1.00 & 1.00 & - & 4.2 & 1.5 to 11.6 & 1.00 & 1.00 & - & 36.4 & 30.8 to 42.3 & 1.00 & & & 120,173 & 76,130 & 210,361 \\
\hline 1 & 2.2 & 1.4 to 3.6 & 0.76 & 0.34 & 0.10 to 1.10 & 3.8 & 2.4 to 6.1 & 0.90 & 0.72 & 0.15 to 3.21 & 54.7 & 51.4 to 58.0 & 2.11 & 1.52 & 1.03 to 2.24 & 368,606 & 319,567 & 585,1049 \\
\hline $2+$ & 6.3 & 3.5 to 11.2 & 2.25 & 0.49 & 0.12 to 1.83 & 10.3 & 7.0 to 15.0 & 2.60 & 0.90 & 0.18 to 4.49 & 74.2 & 68.3 to 79.4 & 5.04 & 1.86 & 1.09 to 3.15 & 108,212 & 126,241 & 169,322 \\
\hline \multicolumn{19}{|c|}{ Number of lifetime sexual partners } \\
\hline $1-4$ & 2.4 & 1.4 to 4.2 & 1.00 & 1.00 & - & 2.1 & 1.1 to 4.0 & 1.00 & 1.00 & - & 43.5 & 40.0 to 47.1 & 1.00 & 1.00 & - & 321,482 & 218,391 & 503,894 \\
\hline $5-9$ & 2.8 & 1.4 to 5.2 & 1.15 & 0.87 & 0.32 to 2.32 & 6.2 & 3.7 to 10.3 & 3.07 & 2.40 & 0.90 to 6.37 & 63.8 & 58.5 to 68.7 & 2.29 & 1.96 & 1.43 to 2.69 & 150,267 & 161, 289 & 252,453 \\
\hline $10+$ & 5.4 & 2.9 to 9.7 & 2.29 & 1.39 & 0.45 to 4.18 & 9.9 & 6.5 to 14.7 & 5.12 & 3.76 & 1.19 to 11.8 & 69.6 & 63.9 to 74.7 & 2.97 & 2.11 & 1.41 to 3.13 & 121,234 & 141,254 & 202,373 \\
\hline \multicolumn{19}{|c|}{ Condom used for most recent sex with most recent partner } \\
\hline Yes & 2.8 & 1.5 to 5.3 & 1.00 & 1.00 & - & 3.4 & 1.6 to 7.0 & 1.00 & 1.00 & - & 51.6 & 46.9 to 56.3 & 1.00 & 1.00 & - & 202,314 & 170,303 & 330,586 \\
\hline No & 3.6 & 2.4 to 5.4 & 1.28 & 1.59 & 0.67 to 3.74 & 6.3 & 4.4 to 8.9 & 1.90 & 1.88 & 0.81 to 4.32 & 58.0 & 54.6 to 61.3 & 1.30 & 1.01 & 0.74 to 1.35 & 352,613 & 328,592 & 567,1027 \\
\hline \multicolumn{19}{|c|}{ Concurrent partnerships in last year** } \\
\hline No & 2.7 & 1.8 to 4.2 & 1.00 & 1.00 & - & 4.3 & 2.9 to 6.4 & 1.00 & 1.00 & - & 51.0 & 47.8 to 54.2 & 1.00 & 1.00 & - & 439,706 & 361,639 & 710,1256 \\
\hline Yes & 6.3 & 2.9 to 13.4 & 2.40 & 1.34 & 0.48 to 3.70 & 8.1 & 4.1 to 15.3 & 1.95 & 0.75 & 0.27 to 2.00 & 74.6 & 67.1 to 80.8 & 2.81 & 1.46 & 0.93 to 2.28 & 66,134 & 78,146 & 105,196 \\
\hline Unknown & 3.1 & 1.3 to 7.2 & 1.14 & 1.13 & 0.38 to 3.31 & 7.8 & 4.3 to 13.9 & 1.88 & 1.46 & 0.62 to 3.38 & 64.6 & 57.5 to 71.2 & 1.76 & 1.53 & 1.02 to 2.28 & 73,127 & 76,144 & 117,226 \\
\hline
\end{tabular}

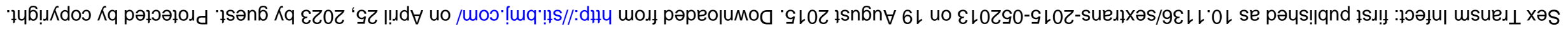




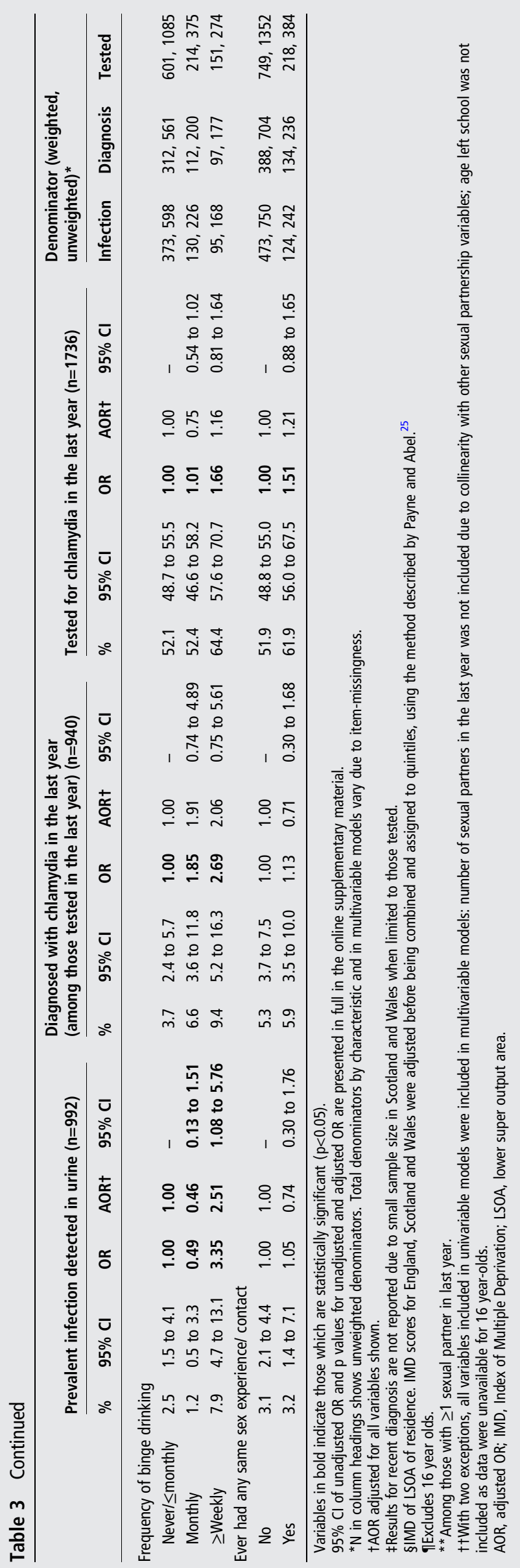

DISCUSSION

Principal findings

In 2010-2012, chlamydia was a common, and commonly diagnosed, infection among young adults in Britain. Diagnoses had arisen following both opportunistic screening and clinically indicated testing in roughly equal numbers. Living in more deprived areas was significantly associated with prevalent infection after adjusting for socio-demographic and behavioural factors. The proportion reporting chlamydia testing was generally greater among those reporting factors associated with chlamydia. However, substantial proportions of young adults reporting risk factors for chlamydia had not been recently tested.

\section{Strengths and limitations}

The major strength of our study is that we used individual-level data from a nationally representative sample. We linked behavioural and biological data to examine a range of risk factors for different outcomes within the same survey and carried out multivariable analyses incorporating socio-demographic and behavioural data to minimise confounding of associations between predictor and outcome variables. There were some limitations. The number of participants aged under 25 limited statistical power to explore all associations of potential interest. For example, while recent testing was found to be higher in England than Scotland or Wales, consistent with chlamydia screening being offered opportunistically as part of an organised programme, the sample size was not large enough to determine whether factors associated with infection differed by country. Given the relatively small absolute numbers of prevalent infections, the proportions in specific subgroups should be interpreted with caution. Our findings may be affected by who agreed to take part in the survey or provide a urine sample. Survey weights were used to minimise bias, but unmeasured bias remains feasible. Our comparisons between risk factors for prevalent infection and recent testing may have been affected by the estimation of outcomes among different denominators. We explored this further in a sensitivity analysis, which showed no notable difference between ORs for testing when estimated in sexually experienced participants versus urine study participants (data not shown). A further limitation is the accuracy of self-reporting. Detailed questions were answered via self-completion, which we expect to have minimised social desirability bias.

Chlamydia infection was measured in urine. This may have missed some infections in women among whom vulvovaginal swabs demonstrate marginally higher sensitivity. ${ }^{26}$ Urine sampling will also have missed rectal infections, leading to underestimation of the total currently infected with chlamydia. However, the impact on our findings is likely minimal as men who have sex with men made up a small proportion of our sample. $^{27}$

\section{Comparison to other studies/data}

Estimates of chlamydia prevalence among young adults in Natsal-3 are comparable to those from other nationally representative surveys from Europe and high-income countries. ${ }^{3}$ Chlamydia prevalence is also similar to that reported in the previous Natsal (conducted in 1999-2001), where prevalence for 18-24 year olds was estimated at 3.0\% in women and $2.7 \%$ in men. ${ }^{22}$ Comparisons between the surveys should be made with caution due to differences between them ${ }^{17}$ and because they were not powered to detect a change in prevalence. Recent testing was not associated with area-level deprivation in our 
Table 4 Percentage, unadjusted and adjusted ORs for prevalent chlamydia infection, self-reported diagnosis in the last year and self-reported testing by socio-demographic and behavioural factors (sexually experienced 16-24 year old men)

\begin{tabular}{|c|c|c|c|c|c|c|c|c|c|c|c|c|c|c|c|c|c|c|}
\hline & \multicolumn{5}{|c|}{ Prevalent infection detected in urine $(n=840)$} & \multicolumn{5}{|c|}{$\begin{array}{l}\text { Diagnosed with chlamydia in the last year (among } \\
\text { those tested in the last year) }(n=471)\end{array}$} & \multicolumn{5}{|c|}{ Tested for chlamydia in the last year $(n=1375)$} & \multicolumn{3}{|c|}{$\begin{array}{l}\text { Denominator (weighted, } \\
\text { unweighted)* }\end{array}$} \\
\hline & $\%$ & $95 \% \mathrm{Cl}$ & OR & AORT & $95 \% \mathrm{Cl}$ & $\%$ & $95 \% \mathrm{Cl}$ & OR & AORT & $95 \% \mathrm{Cl}$ & $\%$ & $95 \% \mathrm{Cl}$ & OR & AORt & $95 \% \mathrm{Cl}$ & Infection & Diagnosis & Tested \\
\hline \multicolumn{19}{|l|}{ Age group } \\
\hline $16-19$ & $0.3 \%$ & 0.1 to 1.4 & 1.00 & 1.00 & - & $4.7 \%$ & 2.4 to 9.0 & 1.00 & 1.00 & - & $40.4 \%$ & 35.9 to 45.1 & 1.00 & 1.00 & - & 234,343 & 151,226 & 374,582 \\
\hline $20-24$ & $3.4 \%$ & 2.2 to 5.2 & 10.6 & 7.54 & 1.37 to 41.3 & $6.7 \%$ & 3.9 to 11.1 & 1.46 & 0.76 & 0.26 to 2.15 & $31.1 \%$ & 27.8 to 34.7 & 0.67 & 0.53 & 0.37 to 0.73 & 391,497 & 192,245 & 629,793 \\
\hline \multicolumn{19}{|l|}{ Countrył } \\
\hline England & $1.9 \%$ & 1.2 to 3.0 & 1.00 & 1.00 & - & & & & & & $37.3 \%$ & 34.3 to 40.3 & 1.00 & 1.00 & - & 532,719 & 316,440 & 859,1181 \\
\hline Scotland & $5.7 \%$ & 2.1 to 14.3 & 3.13 & 3.16 & 0.78 to 12.8 & & & & & & $22.2 \%$ & 14.0 to 33.5 & 0.48 & 0.33 & 0.16 to 0.64 & 60,72 & 20,22 & 89,111 \\
\hline Wales & $1.7 \%$ & 0.2 to 12.1 & 0.88 & 1.20 & 0.18 to 7.63 & & & & & & $12.8 \%$ & 6.9 to 22.3 & 0.25 & 0.19 & 0.08 to 0.40 & 33,49 & 7,9 & 55,83 \\
\hline \multicolumn{19}{|c|}{ IMD quintile of LSOA of residence§ } \\
\hline 2 least deprived & $1.3 \%$ & 0.4 to 3.6 & 1.00 & 1.00 & - & $5.2 \%$ & 2.5 to 10.5 & 1.00 & 1.00 & - & $34.5 \%$ & 30.0 to 39.2 & 1.00 & 1.00 & - & 241,315 & 127,180 & 369,509 \\
\hline Middle quintile & $1.6 \%$ & 0.6 to 4.4 & 1.24 & 1.01 & 0.15 to 6.68 & $5.0 \%$ & 1.7 to 13.8 & 0.96 & 0.68 & 0.15 to 2.97 & $33.3 \%$ & 27.4 to 39.9 & 0.95 & 1.04 & 0.70 to 1.52 & 114,164 & 60,86 & 183,263 \\
\hline 2 most deprived & $3.4 \%$ & 2.1 to 5.6 & 2.71 & 3.75 & 1.11 to 12.5 & $6.5 \%$ & 3.6 to 11.4 & 1.26 & 1.06 & 0.42 to 2.64 & $35.2 \%$ & 31.1 to 39.5 & 1.03 & 1.13 & 0.82 to 1.53 & 269,361 & 155,205 & 450,603 \\
\hline \multicolumn{19}{|l|}{ Age left schoolq †† } \\
\hline $17+$ & $1.6 \%$ & 0.9 to 2.7 & 1.00 & & & $5.3 \%$ & 3.1 to 9.0 & 1.00 & & & $33.6 \%$ & 30.4 to 37.1 & 1.00 & & & 439,568 & 233, 304 & 703,927 \\
\hline 16 & $5.0 \%$ & 2.7 to 9.2 & 3.28 & & & $7.2 \%$ & 3.6 to 13.8 & 1.38 & & & $37.8 \%$ & 32.3 to 43.5 & 1.20 & & & 143,206 & 87,134 & 230,334 \\
\hline \multicolumn{19}{|c|}{ Age at first heterosexual sex } \\
\hline $17+$ & $1.0 \%$ & 0.3 to 2.8 & 1.00 & 1.00 & - & $2.8 \%$ & 0.7 to 9.9 & 1.00 & 1.00 & - & $25.6 \%$ & 21.4 to 30.3 & 1.00 & 1.00 & - & 210,245 & 87,112 & 340,431 \\
\hline 16 & $1.5 \%$ & 0.5 to 4.6 & 1.49 & 1.14 & 0.27 to 4.74 & $4.7 \%$ & 1.8 to 11.8 & 1.75 & 1.14 & 0.24 to 5.30 & $33.4 \%$ & 27.9 to 39.4 & 1.46 & 1.13 & 0.75 to 1.67 & 148,205 & 84,108 & 253,351 \\
\hline$<16$ & $4.0 \%$ & 2.4 to 6.5 & 4.18 & 1.65 & 0.55 to 4.90 & $7.8 \%$ & 4.7 to 12.6 & 2.99 & 1.58 & 0.37 to 6.62 & $45.3 \%$ & 40.7 to 49.9 & 2.40 & 1.53 & 1.07 to 2.19 & 238,352 & 167,243 & 376,539 \\
\hline \multicolumn{19}{|c|}{ Number of sexual partners in the last yeart† } \\
\hline 0 or 1 & $1.5 \%$ & 0.7 to 3.0 & 1.00 & & & $3.4 \%$ & 1.5 to 7.8 & 1.00 & & & $26.0 \%$ & 22.6 to 29.7 & 1.00 & & & 359,466 & 145,196 & 568,768 \\
\hline 2 & $1.3 \%$ & 0.4 to 4.2 & 0.86 & & & $0.9 \%$ & 0.2 to 3.9 & 0.27 & & & $40.3 \%$ & 33.2 to 47.7 & 1.92 & & & 123,159 & 74,99 & 185,251 \\
\hline $3-4$ & $3.1 \%$ & 1.1 to 8.5 & 2.16 & & & $1.5 \%$ & 0.4 to 6.2 & 0.44 & & & $43.0 \%$ & 35.5 to 50.9 & 2.15 & & & 70,110 & 57,83 & 134,194 \\
\hline $5+$ & $7.5 \%$ & 3.7 to 14.6 & 5.47 & & & $21.2 \%$ & 12.9 to 32.7 & 7.54 & & & $60.9 \%$ & 51.8 to 69.3 & 4.42 & & & 67,100 & 63,89 & 103,146 \\
\hline \multicolumn{19}{|c|}{ Number of new sexual partners in the last year } \\
\hline 0 & $1.8 \%$ & 0.9 to 3.8 & 1.00 & 1.00 & - & $5.5 \%$ & 2.3 to 12.6 & 1.00 & 1.00 & - & $26.0 \%$ & 22.0 to 30.5 & 1.00 & 1.00 & - & 263,335 & 108,136 & 416,540 \\
\hline 1 & $0.8 \%$ & 0.2 to 2.5 & 0.42 & 0.33 & 0.05 to 2.06 & $4.0 \%$ & 1.7 to 9.0 & 0.71 & 1.13 & 0.09 to 13.9 & $36.7 \%$ & 31.8 to 41.8 & 1.64 & 1.28 & 0.88 to 1.85 & 203,270 & 115,161 & 323,452 \\
\hline $2+$ & $5.1 \%$ & 2.9 to 8.8 & 2.87 & 0.47 & 0.09 to 2.45 & $8.0 \%$ & 4.5 to 13.7 & 1.48 & 2.87 & 0.26 to 30.7 & $46.3 \%$ & 40.7 to 52.0 & 2.45 & 1.06 & 0.67 to 1.68 & 152,229 & 115,170 & 251,366 \\
\hline \multicolumn{19}{|c|}{ Number of sexual partners in the last year without a condom } \\
\hline 0 & $0.3 \%$ & 0.1 to 1.3 & 1.00 & 1.00 & - & $1.8 \%$ & 0.4 to 8.4 & 1.00 & 1.00 & - & $27.0 \%$ & 22.4 to 32.1 & 1.00 & 1.00 & - & 205,248 & 88,115 & 331,450 \\
\hline 1 & $1.7 \%$ & 0.8 to 3.6 & 5.26 & 1.23 & 0.09 to 15.2 & $4.9 \%$ & 2.6 to 8.9 & 2.75 & 0.78 & 0.19 to 3.15 & $34.3 \%$ & 30.2 to 38.7 & 1.41 & 1.12 & 0.72 to 1.71 & 287,396 & 160,222 & 475,640 \\
\hline $2+$ & $6.5 \%$ & 3.9 to 10.9 & 21.3 & 4.95 & 0.42 to 57.9 & $10.9 \%$ & 6.0 to 19.0 & 6.51 & 0.46 & 0.11 to 1.83 & $48.8 \%$ & 42.3 to 55.4 & 2.59 & 1.37 & 0.80 to 2.34 & 130,194 & 95,134 & 194,281 \\
\hline \multicolumn{19}{|c|}{ Number of lifetime sexual partners } \\
\hline $1-4$ & $0.4 \%$ & 0.1 to 1.5 & 1.00 & 1.00 & - & $1.0 \%$ & 0.3 to 3.1 & 1.00 & 1.00 & - & $25.3 \%$ & 21.8 to 29.2 & 1.00 & 1.00 & - & 332,412 & 133,176 & 524,706 \\
\hline $5-9$ & $1.2 \%$ & 0.3 to 4.0 & 3.21 & 1.78 & 0.20 to 15.5 & $3.8 \%$ & 1.3 to 10.8 & 4.15 & 4.87 & 0.58 to 40.2 & $39.6 \%$ & 33.6 to 45.9 & 1.93 & 1.50 & 1.01 to 2.21 & 141,200 & 84,123 & 222,314 \\
\hline $10+$ & $7.6 \%$ & 4.8 to 11.7 & 22.6 & 8.69 & 1.21 to 62.0 & $12.3 \%$ & 7.6 to 19.2 & 14.6 & 19.80 & 3.03 to 129 . & $49.2 \%$ & 43.2 to 55.2 & 2.86 & 2.23 & 1.45 to 3.42 & 148,224 & 121,167 & 247,342 \\
\hline \multicolumn{19}{|c|}{ Condom used for most recent sex with most recent partner } \\
\hline Yes & $0.7 \%$ & 0.2 to 2.0 & 1.00 & 1.00 & - & $4.3 \%$ & 2.0 to 8.9 & 1.00 & 1.00 & - & $33.5 \%$ & 29.7 to 37.6 & 1.00 & 1.00 & - & 301, 391 & 163,221 & 491,671 \\
\hline No & $4.1 \%$ & 2.6 to 6.4 & 6.03 & 3.59 & 0.77 to 16.6 & $7.4 \%$ & 4.5 to 12.0 & 1.79 & 1.06 & 0.35 to 3.21 & $38.0 \%$ & 33.9 to 42.4 & 1.22 & 0.97 & 0.70 to 1.34 & 283,398 & 172,237 & 458,621 \\
\hline \multicolumn{19}{|c|}{ Concurrent partnerships in last year** } \\
\hline No & $2.6 \%$ & 1.6 to 4.2 & 1.00 & 1.00 & - & $6.7 \%$ & 4.1 to 10.8 & 1.00 & 1.00 & - & $32.9 \%$ & 29.6 to 36.3 & 1.00 & 1.00 & - & 418,557 & 219,298 & 676,916 \\
\hline Yes & $2.0 \%$ & 0.7 to 5.4 & 0.75 & 0.18 & 0.04 to 0.71 & $6.5 \%$ & 2.7 to 14.8 & 0.96 & 0.60 & 0.19 to 1.79 & $49.7 \%$ & 41.0 to 58.4 & 2.02 & 1.52 & 0.92 to 2.50 & 82,121 & 67,92 & 136,188 \\
\hline Unknown & $1.7 \%$ & 0.5 to 5.6 & 0.64 & 0.60 & 0.11 to 3.00 & $1.3 \%$ & 0.3 to 5.5 & 0.19 & 0.06 & 0.00 to 0.71 & $38.5 \%$ & 30.9 to 46.7 & 1.28 & 1.18 & 0.77 to 1.80 & 92,122 & 52,75 & 137,193 \\
\hline
\end{tabular}




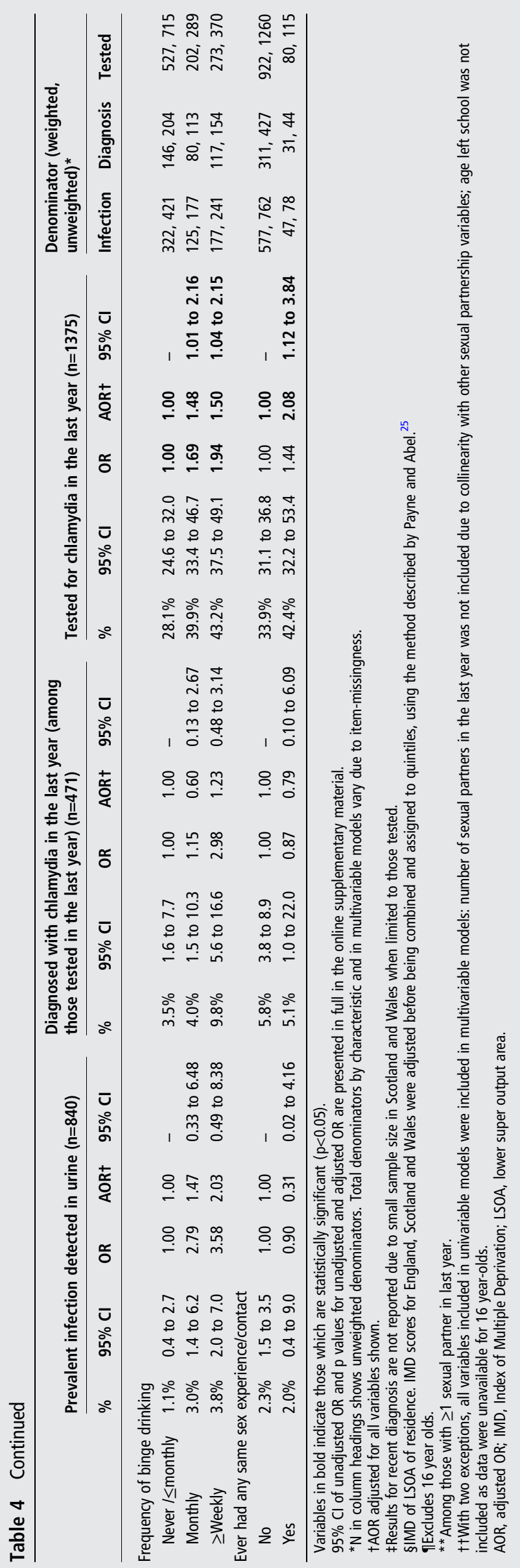

study. This is contrary to an analysis of data from the southeast of England, which found higher rates of chlamydia screening in more deprived areas in $2008 .^{28}$ This difference in findings may reflect the different study period, when screening coverage was lower, or regional variation in screening patterns.

National surveillance data on chlamydia tests and diagnoses among 15-24 year olds are available for England for the period covered by Natsal-3. The average coverage of chlamydia testing in England in 2010-2012 among 15-24 year olds was 40\% in women and $20 \%$ in men. ${ }^{14} 15$ This is lower than the $57 \%$ of women and $37 \%$ of men resident in England who reported a test in the last year in Natsal-3. Differences between denominators (all vs sexually experienced only) and age ranges (surveillance data for this period use partly aggregated data and are not available for 16-24 year olds) may partly explain these differences. Applying the proportion of $16-24$ year olds with $\geq 1$ sexual partner estimated in Natsal-3 $(80 \%)^{27}$ to surveillance data results in an estimated coverage per year of $51 \%$ and $25 \%$ among sexually experienced women and men, respectively. This is more comparable but still somewhat lower than our estimates. This may indicate some residual bias arising from who took part in Natsal-3. Our findings on location of last test among those recently diagnosed are consistent with 2011 surveillance data, where $42 \%$ of diagnoses among 15-24 year olds were reported from GUM clinics, 15\% from family planning services, $7 \%$ from GPs, 2\% from education and 33\% from other/unknown settings. ${ }^{14}$ The proportion of diagnoses from GPs was higher in Natsal-3 (27\%) than in surveillance data. This may reflect the partially aggregate nature of surveillance data as a large proportion of diagnoses made in other/unknown settings are likely to be from GPs.

\section{Implications for chlamydia control in Britain}

Encouragingly, those reporting risk factors for chlamydia were generally more likely to report having been recently tested. This is contrary to uptake patterns often seen in public health interventions, where those in most need are often least likely to access care. ${ }^{29}$ However, at least one-quarter of women and around half of men reporting a risk factor associated with prevalent infection had not been recently tested. This presents a clear potential for ongoing transmission of chlamydia from high risk but untested individuals. Almost all prevalent infections in men were among 20-24 year olds, less than a third of whom reported recent testing. As young women tend to have slightly older male partners, ${ }^{30}$ sexual mixing patterns by age may play a key role in transmission.

Our findings suggest that the likelihood of having an infection diagnosed and treated varies by deprivation, as although screening coverage was uniform by area-level deprivation, chlamydia prevalence was higher in those living in more deprived areas. This raises the question as to whether efforts to expand or intensify chlamydia screening should prioritise those living in more deprived areas to address this potential inequality. A high proportion of infections were found in those who had not used a condom at last sex, and around one-fifth of recent diagnoses were made following a test prompted by a partner having chlamydia, which emphasises the importance of condom use and partner notification in chlamydia prevention and control.

\section{Unanswered questions and future research}

Increased screening and prevention efforts among individuals living in deprived areas and those reporting risk factors for chlamydia who are not regularly accessing screening may reduce the 

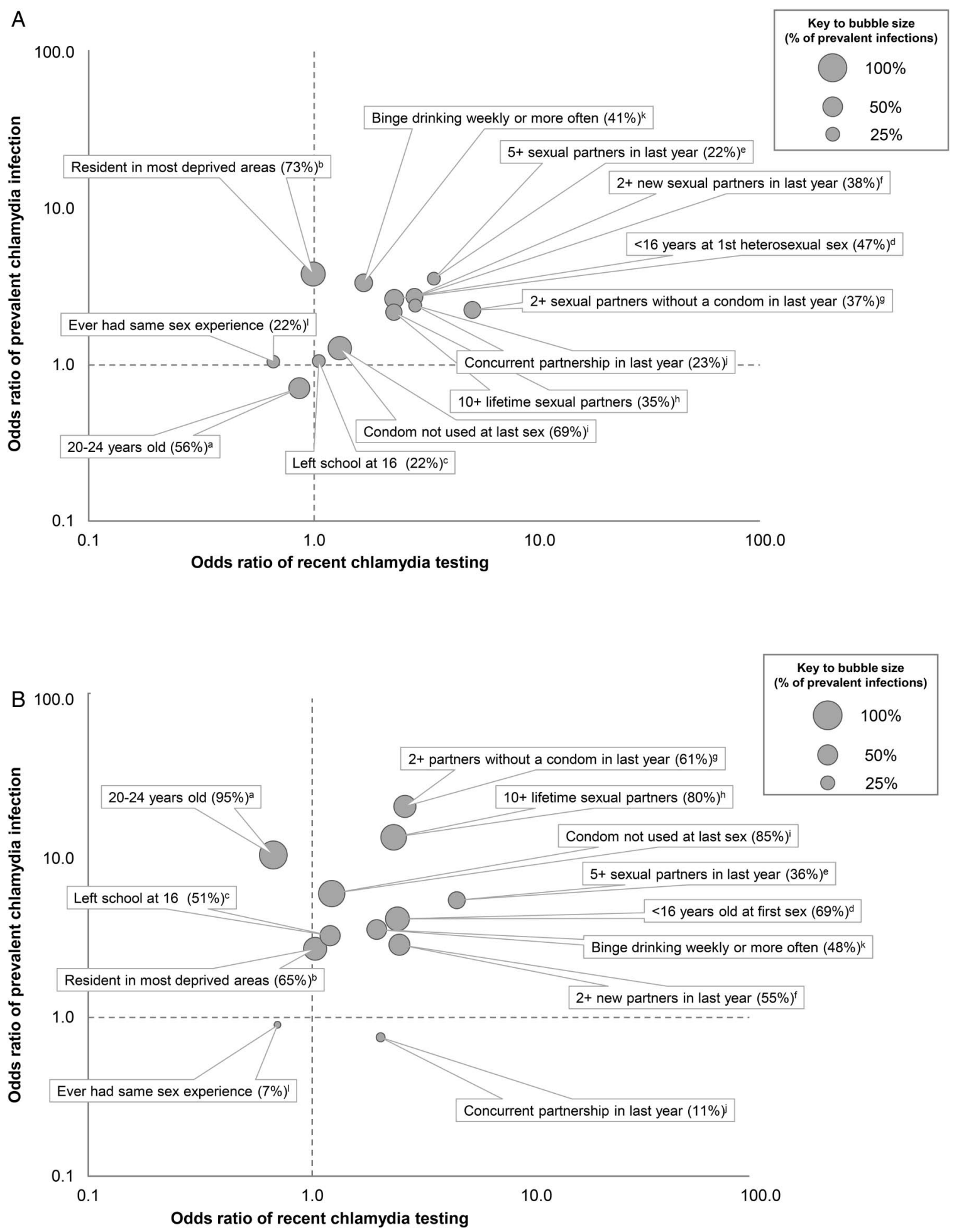

Figure 1 Bubble plot showing unadjusted ORs for prevalent chlamydia infection compared with recent testing by socio-demographic and behavioural factors, and proportion of prevalent infections in each group (16-year-old to 24-year-old sexually experienced women (A) and men (B)). Factors in the upper-right-hand quadrant are those where both the odds of prevalent infection and of testing were higher than the reference group. Factors in the upper-left-hand quadrant show those where the odds of prevalent infection were higher, but odds of testing were lower than the reference group (for ORs, $95 \% \mathrm{Cls}$ and denominators, see tables 3 and 4). The area of the bubble and percentage in parentheses represents the proportion of individuals with a prevalent infection who reported the specified characteristic (for $95 \%$ Cls, see online supplementary table S1). Letters indicate reference groups: (a) 16-19 years old; (b) resident in lower super output area in the two least deprived quintiles, as measured by the Index of Multiple Deprivation; (c) left school at 17+ (among those aged $\geq 16$ ); (d) 17+ years at first heterosexual sex; (e) 0 or 1 sexual partners in the last year; (f) 0 new sexual partners in the last year; ( $g$ ) 0 sexual partners in the last year without a condom; (h) 1-9 lifetime sexual partners; (i) condom used at last sex; (j) no concurrent partnership in last year (among those with 1+ more sexual partners in last year); (k) reports binge drinking never or less than monthly; and (I) never had same sex contact/experience. 
prevalence of undiagnosed infection and decrease transmission. The relative costs, feasibility and acceptability of different approaches to chlamydia screening warrant careful consideration in light of our findings.

\section{Key messages}

- Using a nationally representative sample of the British population, we compared factors associated with chlamydia prevalence, testing and diagnosis among 16-year-old to 24-year-old women and men.

- The proportion reporting chlamydia testing was generally greater among those reporting factors associated with chlamydia (eg, among those with more sexual partners).

- However, substantial proportions of young adults reporting risk factors for chlamydia had not been recently tested.

- Greater screening and prevention efforts among individuals living in deprived areas and those reporting risk factors for chlamydia who are not regularly accessing screening may reduce the prevalence of undiagnosed infection and decrease transmission.

\section{Author affiliations}

${ }^{1}$ Research Department of Infection and Population Health, University College London, London, UK

${ }^{2}$ Centre for Infectious Disease Surveillance \& Control (CIDSC), Public Health England, London, UK

${ }^{3}$ NatCen Social Research, London, UK

${ }^{4}$ Microbiology Services, Public Health England, London, UK

${ }^{5}$ Department of Social and Environmental Health Research, London School of Hygiene and Tropical Medicine, London, UK

\section{Handling editor Jackie A Cassell}

Twitter Follow Nigel Field at @UCL_SexHealth, @PHE_uk and @NatCen

Acknowledgements Natsal-3 is a collaboration between University College London (London, UK), the London School of Hygiene and Tropical Medicine (London, UK), NatCen Social Research, Public Health England (formerly the Health Protection Agency) and the University of Manchester (Manchester, UK). We thank the study participants; the team of interviewers from NatCen Social Research; and operations and computing staff from NatCen Social Research; staff from the Department of HIV and Sexually Transmitted Infections, Public Health England for data linkage, anonymisation, and data entry; and laboratory staff from the Virus Reference Department, Public Health England for their contributions to development of protocols and testing.

Contributors SCW, KS, PSO, CHM, and AMJ conceived this article. SCW did the statistical analysis, with support from CHM, CT and AJC. CHM, AJC, KW, CAI, PSo and AMJ were initial applicants on Natsal-3, wrote the study protocol and obtained funding. CT, KS, PSo, CHM, NF, SC, AJC, KW, SA, CAI and AMJ designed the Natsal-3 questionnaire, applied for ethics approval and undertook piloting of the questionnaire. CT, CHM and SC managed the data. PSa and FS did the laboratory testing, with support from SA and CAI. SCW wrote the first draft. All authors interpreted data, reviewed successive drafts and approved the final version of the article.

Funding The study was supported by grants from the Medical Research Council (G0701757) and the Wellcome Trust (084840), with contributions from the Economic and Social Research Council and Department of Health. NF is supported by a National Institute for Health Research Academic Clinical Lectureship.

Competing interests AM Johnson has been a Governor of the Wellcome Trust since 2011.

Ethics approval Natsal-3 was approved by Oxfordshire Research Ethics Committee A (Ref: 09/H0604/27). The ethical rationale for anonymised STI testing has been described. ${ }^{30}$

Provenance and peer review Not commissioned; externally peer reviewed.

Data sharing statement The Natsal-3 data will be archived with the UK Data Archive and further details are available from the Natsal website (www.natsal.ac.uk).

Open Access This is an Open Access article distributed in accordance with the terms of the Creative Commons Attribution (CC BY 4.0) license, which permits others to distribute, remix, adapt and build upon this work, for commercial use, provided the original work is properly cited. See: http://creativecommons.org/ licenses/by/4.0/

\section{REFERENCES}

1 Public Health England. Table 8: Number and rates of selected STI diagnoses in the UK, 2008-2012. https://www.gov.uk/government/statistics/sexually-transmittedinfections-stis-annual-data-tables (accessed June 2014).

2 Kalwij S, Macintosh M, Baraitser P. Screening and treatment of chlamydia trachomatis infections. BMJ 2010;340:912-17.

3 European Centre for Disease Prevention and Control. Chlamydia control in Europe: literature review. 2014. http://ecdc.europa.eu/en/publications/Publications/ chlamydia-control-europe.pdf (accessed May 2015).

4 Turner KM, Adams EJ, LaMontagne DS, et al. Modelling the effectiveness of chlamydia screening in England. Sex Transm Infect 2006;82:496-502.

5 Public Health England. National Chlamydia Screening Programme Standards. 7th edn. 2014. http://www.chlamydiascreening.nhs.uk/ps/standards.asp (accessed May 2015).

6 Scottish Intercollegiate Guidelines Network. Management of genital Chlamydia trachomatis infection. A national clinical guideline (109). Edinburgh: Scottish Intercollegiate Guidelines Network, 2009. http://www.sign.ac.uk/pdf/grg109.pdf (accessed May 2015).

7 European Centre for Disease Prevention and Control. Chlamydia control in Europea survey of Member States. 2014. http://www.ecdc.europa.eu/en/publications/ Publications/chlamydia-control-survey-europe-2012.pdf (accessed: May 2015).

8 Welsh Assembly Government. Sexual Health and Wellbeing Action Plan for Wales, 2010-2015. 2009. http://gov.wales/topics/health/improvement/index/sexualhealth/? lang=en (accessed May 2015).

9 Health Protection Agency. Testing Times-HIV and other Sexually Transmitted Infections in the United Kingdom: 2007. 2007. http://webarchive.nationalarchives. gov.uk/20140714084352/http://www.hpa.org.uk/web/HPAweb\&HPAwebStandard/ HPAweb_C/1203084355941 (accessed May 2015).

10 Scottish Executive. Respect and Responsibility. Strategy and Action Plan for Improving Sexual Health. 2005. http://www.scotland.gov.uk/Resource/Doc/35596/ 0012575.pdf (accessed: May 2015).

11 The National Assembly for Wales. A strategic framework for promoting sexual health in Wales. 2001. http://www.wales.nhs.uk/sitesplus/documents/888/ WAGStrategicFramework.pdf (accessed May 2015).

12 Skidmore $\mathrm{S}$, Horner $\mathrm{P}$, Mallinson $\mathrm{H}$. Testing specimens for Chlamydia trachomatis. Sex Transm Infect 2006;82:272-5.

13 National Audit Office. Young people's sexual health: the National Chlamydia Screening Programme. London: The Stationery Office, 2009. http://www.nao.org.uk/ report/department-of-health-young-peoples-sexual-health-the-national-chlamydiascreening-programme/ (accessed May 2015).

14 Health Protection Agency. Genital Chlamydia trachomatis diagnoses in young adults in England, 2011. 2012. http://webarchive.nationalarchives.gov.uk/20140714084352/ http://www.hpa.org.uk/hpr/archives/2012/hpr2212.pdf (accessed: May 2015).

15 Public Health England. Sexually transmitted infections and chlamydia screening in England, 2012. 2013. http://webarchive.nationalarchives.gov.uk/20140714084352/ http://www.hpa.org.uk/hpr/archives/2013/hpr2313.pdf (accessed: May 2015).

16 Erens B, Phelps A, Clifton $S$, et al. Methodology of the third British National Survey of Sexual Attitudes and Lifestyles (Natsal-3). Sex Transm Infect 2014;90:84-9.

17 Sonnenberg P, Clifton S, Beddows S, et al. Prevalence, risk factors, and uptake of interventions for sexually transmitted infections in Britain: findings from the National Surveys of Sexual Attitudes and Lifestyles (Natsal). Lancet 2013;382: 1795-806.

18 Craig R, Mindell J, eds. Health survey for England 2010—volume 1: respiratory health. Leeds: NHS Information Centre, 2011. http://www.hscic.gov.uk/catalogue/ PUB03023/heal-surv-eng-2010-resp-heal-ch1-intr.pdf (accessed May 2015).

19 Park A, Clery E, Curtice J, et al., eds. British social attitudes: the 29th report. London: Natcen Social Research, 2012. http://www.bsa-29.natcen.ac.uk (accessed: May 2015).

20 Erens B, Phelps A, Clifton S, et al. The Third National Survey of Sexual Attitudes and Lifestyles (Natsal-3): technical report. London: National Centre for Social Research, 2013. http://www.natsal.ac.uk (accessed May 2015).

21 Fenton KA, Korovessis C, Johnson AM, et al. Sexual behaviour in Britain: reported sexually transmitted infections and prevalent genital Chlamydia trachomatis infection. Lancet 2001;358:1851-4.

22 Sheringham J, Mann S, Simms I, et al. It matters what you measure: a systematic literature review examining whether young people in poorer socioeconomic circumstances are more at risk of chlamydia. Sex Transm Infect 2013;89:175-80.

23 Cook RL, Clark DB. Is there an association between alcohol consumption and sexually transmitted diseases? A systematic review. Sex Transm Dis 2005;32:156-64.

24 Payne RA, Abel GA. UK indices of multiple deprivation - a way to make comparisons across constiuent countries easier. Health Stat Q 2012;53:22-37. 
25 Lanjouw E, Ossewaarde JM, Stary A, et al. 2010 European guideline for the management of Chlamydia trachomatis infections. Int J STD AIDS 2010;21: 729-37.

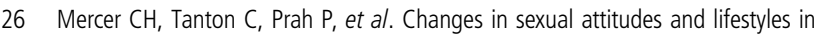
Britain through the life course and over time: findings from the National Surveys of Sexual Attitudes and Lifestyles (Natsal). Lancet 2013;382: 1781-94.

27 Johnson SA, Simms I, Sheringham J, et al. The implementation of chlamydia screening: a cross-sectional study in South East of England. Sex Tranm Infect 2010;86:217-21.
28 Marmot M, Allen J, Goldblatt P, et al. Fair Society, Healthy Lives (The Marmot Review). The Marmot Review, 2010. http://www.instituteofhealthequity.org/projects/ fair-society-healthy-lives-the-marmot-review (accessed May 2015).

29 Mercer $\mathrm{CH}$, Copas AJ, Sonnenberg $\mathrm{P}$, et al. Who has sex with whom? Characteristics of heterosexual partnerships reported in the second National Survey of Sexual Attitudes and Lifestyles. International Journal of Epidemiology 2009;38:206-2014.

30 Field N, Tanton $\mathrm{C}$, Mercer $\mathrm{CH}$, et al. Testing for sexually transmitted infections in a population-based sexual health survey: development of an acceptable ethical approach. J Med Ethics 2012;38:380-2. 